\title{
An assessment of liver function test in typhoid fever in children
}

\author{
Jain $\mathbf{H}^{1}$, Arya $\mathrm{S}^{2}$, Ikram $\mathrm{S}^{3}$, Mandloi $\mathbf{R}^{4}$, Xess $\mathbf{V}^{5}$ \\ ${ }^{1}$ Dr Hemant Jain, Professor, ${ }^{2}$ Dr Sunil Arya, Assistant Professor, ${ }^{3}$ Dr Sadaf Ikram, P.G Student, ${ }^{4}$ Dr Rashika Mandloi, \\ P.G Student, ${ }^{5}$ Dr.Virendra Xess, P.G Student; all are attached with Department of Pediatrics, M.G.M. Medical College, \\ Indore (MP).
}

Address for Correspondence: Dr Sunil Arya, Assistant Professor, Department of Pediatrics, M.G.M. Medical College, Indore (MP). E-mail-drsunilarya22@gmail.com

\begin{abstract}
Background: Liver involvement is known in typhoid and may be in the form of hepatomegaly, jaundice, biochemical and histopathological changes. Isolated hepatomegaly is of no clinical significance, but its occurrence with jaundice though rare indicates liver involvement as a result of generalized toxemia or invasion by salmonella. Significant liver damage may have occurred without obvious clinical signs or abnormal laboratory tests. Aim of study: Assessment of liver functionin typhoid fever in children diagnosed by widal agglutination test by biochemical test. Setting: Fifty-four cases of typhoid fever less than 16 years admitted inPaediatric Department MY Hospital, MGM Medical College Indore, comprised the clinical material for the study. Design: Cross sectional study. Method: 54 children with enteric fever were taken after making clinical diagnosis, confirmed by Widaltest and LFT was performed to assess liver involvement. Result: Hepatomegaly was seen in 19 [35\%] cases and tender hepatomegaly was seen in 2 cases of the study group. S.G.O.T was raised in 27 [50\%] cases and S.G.P.T was raised in 25 [46\%] cases out of total 54 cases. Most of the cases with raised S.G.O.T and S.G.P.T presented in the 2nd week of fever. Serum bilirubin was raised in only 2 cases. Statistical Analysis: for statistical analysis Kruskalwallis test was applied. Conclusion: Out of 54 cases S.G.O.T was raised in 27 cases and S.G.P.T in 25 cases. Most cases with raised S.G.O.T and S.G.P.T presented in the s 2 nd week of fever. Serum bilirubin was raised in only 2 cases.
\end{abstract}

Key words: Typhoid, Salmonella, Serum glutamic oxaloacetic transaminase, Serum glutamic pyruvic transaminase, liver function test.

\section{Introduction}

Typhoid fever is a common bacterial infection in the tropics attended with considerable morbidity and mortality.

Hepatic manifestations are not uncommon in enteric fever, this condition was previously called as "hepatitis typhosa" and now termed as typhoid hepatitis, first described by Osler [1].

The incidence of hepatitis in enteric fever was reported more during second to fourth week of illness [2]. Liver involvement may be in the form of hepatomegaly, jaundice, biochemical alterations and histopathological changes. Isolated hepatomegaly is of no clinical

Manuscript received: $14^{\text {th }}$ March 2016

Reviewed: $27^{\text {th }}$ March 2016

Author Corrected; $11^{\text {th }}$ April 2016

Accepted for Publication: $23^{\text {rd }}$ April 2016 significance, but its occurrence with jaundice though rare indicates liver involvement as a result of generalized toxemia or invasion by salmonella organism.

Abnormal liver function test suggesting hepatic involvement has been reported as 23 to $60 \%$ by various studies [3], [4], [5].

Few studies report incidence of elevated transaminases significantly in all the cases in $2^{\text {nd }}$ and $3^{\text {rd }}$ week of illness [6]. As the liver has a great functional reserve, significant liver damage may have occurred without obvious clinical signs or abnormal laboratory tests. The prospective study was planned to review the spectrum of hepatic involvement and to evaluate the severity and outcome of various hepatic manifestations of typhoid fever in children. 


\section{Methodology}

Fifty four cases of typhoid fever in children admitted to the Paediatric Department MY Hospital, MGM Medical College Indore, comprised the clinical material for the study. On admission a detailed history and complete physical examination was carried out in all cases and the findings recorded. Routine investigations carried out included total and differential leucocyte count, haemoglobin estimation, urine analysis and stool examination. A clinical diagnosis of typhoid was made on the basis of history of continuous fever, ill and toxic appearance, coated tongue and in a few cases a palpable spleen. The diagnosis was confirmed by the following investigation:

- Serum widal reaction - the widal reaction was considered as positive when -

i. Titre with $\mathrm{O}$ antigen was more than $1 / 80$.

ii. There was a titre of $1 / 120$ or more with B.typhosum $\mathrm{H}$ antigen and there was no agglutination with other antigens. iii. A rising titre was seen.

\section{- Liver function tests :}

i. Serum bilirubin - total, direct and indirect.

ii . Serum proteins - total, albumin and globulin.

iii. Serum glutamic oxaloacetic transaminase [SGOT] and serum glutamic pyruvic transaminase [SGPT] estimation.

\section{Inclusion criteria}

1. Age group of 2 years to 14 years

2. Fever of more than 7 days.

3. Enteric fever confirmed by tube agglutination test

\section{Exclusion Criteria}

1. Children with other comorbidities like malaria

2. Children with preexistent liver disease.

3. Children with jaundice in last 6 months.

\section{Observation Tables}

A prospective study of 54 patients were carried out during the period from Oct. 2012 to May 2013.

Table No 1: Age and sex distribution of the patients.

\begin{tabular}{|c|c|c|c|c|}
\hline Age group & Males & Females & Total & Percentage \\
\hline 1-4 years & 12 & 4 & 16 & $29.62 \%$ \\
\hline 4-8 years & 6 & 16 & 22 & $40.74 \%$ \\
\hline 8 years and above & 2 & 14 & 16 & $29.62 \%$ \\
\hline Total & 20 & 34 & 54 & $100 \%$ \\
\hline
\end{tabular}

Majority of the cases $40.74 \%$ were in the age group of 4-8 years of age. Out of the 54 cases studied, there were 20 males $(37.03 \%)$ and 34 female $(62.9 \%)$.

Table No 2: Showing the incidence of various symptoms in typhoid cases.

\begin{tabular}{|c|c|c|}
\hline Complaints & No. of cases & Percentage \\
\hline Fever & 54 & $100 \%$ \\
\hline Cough & 26 & $48.14 \%$ \\
\hline Vomiting & 28 & $51.85 \%$ \\
\hline Loose motion & 8 & $14.81 \%$ \\
\hline Abdominal pain & 36 & $66.66 \%$ \\
\hline Loss of appétite & 34 & $62.96 \%$ \\
\hline Abdominal distension & 14 & $25.92 \%$ \\
\hline Swelling all over body & 2 & $7.40 \%$ \\
\hline Jaundice & 2 & $3 \%$ \\
\hline
\end{tabular}


Fever is present in almost all cases. Abdominal pain (66.66\%) of cases and Loss of appetite (62.96\%) seen in majority of cases.

Table No 3: Showing titers in Widal test.

\begin{tabular}{|c|c|c|c|c|}
\hline Titres of & \multicolumn{3}{|c|}{ Age Distribution } & Total \\
\hline & $(1-4$ years $)$ & $(4-8$ years $)$ & (8 years \& above) & 14 \\
\hline $1: 80$ & 6 & 4 & 4 & 22 \\
\hline $1: 320$ & 4 & 14 & 4 & 18 \\
\hline
\end{tabular}

As seen in table, 22 cases had titre of 1:160, in 18 cases titre of 1:320 and in 14 case titre of 1:80 was reported.

Table No 4: Showing SGOT and SGPT value in typhoid cases on admission and on discharge:

\begin{tabular}{|c|c|c|c|c|c|}
\hline \multirow{2}{*}{} & \multirow{2}{*}{ Value } & \multicolumn{2}{|c|}{$\begin{array}{c}\text { SGOT } \\
\text { (units) }\end{array}$} & \multicolumn{2}{c|}{$\begin{array}{c}\text { SGPT } \\
\text { (units) }\end{array}$} \\
\cline { 3 - 6 } & & No. of cases & $\%$ & No. of cases & $\%$ \\
\hline On admission & $>35$ & 27 & $50 \%$ & 29 & $53.70 \%$ \\
\hline On discharge after 7 days of antibiotic & $<35$ & 20 & $74.7 \%$ & 22 & $75.86 \%$ \\
\cline { 2 - 6 } & $>35$ & 07 & $25.92 \%$ & 07 & $24.14 \%$ \\
\hline
\end{tabular}

On admission, SGOT and SGPT levels were found $>35 \mathrm{IU} / \mathrm{L}$ in 27 cases $(50 \%)$ and 29 cases $(53.70 \%)$ respectively. On discharge after 7 days of antibiotic, majority of patients had SGOT and SGPT levels $<35$ IU/L

Table No 5: Showing the degree and characteristics of hepatomegaly in typhoid cases.

\begin{tabular}{|l|c|c|}
\hline Characteristics & No. of Cases & Percentage \\
\hline Extent: & 7 & $36.8 \%$ \\
d. Just palpable & 10 & $52 \%$ \\
e. Below $2.5 \mathrm{~cm}$. & 2 & $10 \%$ \\
f. Above $2.5 \mathrm{~cm}$. & 15 & $78 \%$ \\
\hline Consistency: & 04 & $21 \%$ \\
c. Soft & & $89.4 \%$ \\
d. Firm & 17 & $10.5 \%$ \\
\hline Surface: & 02 & \\
Smooth & & \\
\hline Tenderness & & \\
\hline
\end{tabular}

Out of 19 cases of enlarged liver, in 7 cases Liver was just palpable, 10 were below $2.5 \mathrm{~cm}$. and 2 were above $2.5 \mathrm{~cm}$. The surface of liver was smooth in all cases. Tender liver was seen in only 2 cases.

Table No 6: Showing relationship of Hepatomegaly with SGOT \& SGPT.

\begin{tabular}{|c|c|c|c|c|c|c|}
\hline \multirow{2}{*}{} & \multicolumn{2}{|c|}{$\begin{array}{c}\text { Total } \\
(\mathbf{n = 5 4})\end{array}$} & \multicolumn{2}{c|}{ Cases with Hepatomegaly } & \multicolumn{2}{c|}{ Cases without Hepatomegaly } \\
\cline { 2 - 7 } & No of cases & $\%$ & No of cases & $\%$ & No of cases & $\%$ \\
\hline SGOT (>35U/L) & 27 & $50 \%$ & 19 & $70.3 \%$ & 8 & $29 \%$ \\
\hline SGPT (>35U/L) & 25 & $46.29 \%$ & 12 & $48 \%$ & 13 & $52 \%$ \\
\hline
\end{tabular}

Out of 54 cases, 27 patients had raised SGOT and 25 of them had raised SGPT 


\section{Discussion}

Typhoid fever is a common infection during childhood in our country and has drawn the attention of several workers. The prospective study was carried out in M.Y Hospital, Department of Paediatrics, M.G.M Medical College, Indore [M.P].

A total of 54 admitted Children below 16 years of age with intermittent fever admitted to M.Y H and CNBC and who tested positive for Widal test were taken up for the study.

Typhoid fever has been investigated with regard to its clinical, biochemical and haematological characteristics. Out of the 54 typhoid cases included in this series, there were 20 males (37\%) and 34 females $(63 \%)$.

Majority of children were above 8 years in age, 40.74 percent of our cases had age ranging between 4 and 8 years, 29.62 percents had range of 0 to 4 years and above 8 years.

Fever was present at the time of admission in all cases.Vomiting was present in 51.85 percent of cases. Pain in abdomen, loose motion, abdominal distention were some of the gastro intestinal symptoms. Abdominal pain was seen in 66.66 percent, loose motion was seen in 14.81 percents of cases. 3\% percents had jaundice and swelling over body seen in only 7.40 percent.

A similar study by Thome A, Zein E et al [7] including 25 paediatric cases, they observed fever in $97 \%$ of cases which was similar but diarrhea was found in greater number of children (36\%) as compared to our study. Gastroenteritis was a frequent manifestation in children in $52 \%$ in their study.

In our study, Hepatomegaly was seen in 19 [35\%] cases. S.G.O.T was raised in 27 [50\%] cases and S.G.P.T was raised in 25 [46\%] cases out of total 54 cases .Serum bilirubin was raised in only $2(4 \%)$ cases. Similar results with raised SGOT and SGPT was found in other studies, one by Jagadish $\mathrm{K}$ et al [8], hepatomegaly was seen in $51.6 \%$, raised levels of SGOT in $61.3 \%$ and SGPT in $48.4 \%$.

In another study by Srikanth. N [9], SGOT was found raised in $44 \%$ cases and SGPT was raised in $42 \%$ cases. Hyperbilirubinemia was seen in $10 \%$ patients.
Farzana Shafqat et al [10] found SGOT was raised in $92.1 \%$ and SGPT in $68.3 \%$ of the subjects while hyperbilirubinemia was seen in $12.4 \%$ of the subjects.

Ali Hassan Abro et al [11] studied and found hepatomegaly in $51.9 \%$ cases, jaundice in $13.4 \%$, SGPT raised in $85 \%$ and SGOT in $75 \%$ casesand $\mathrm{M}$ Rasoolinejad et al [12] found hepatomegaly in $52.3 \%$, clinical jaundice $1.8 \%$, SGPT $71 \% \&$ SGOT in $24 \%$ of cases. Most of these showed comparable results with SGOT and SGPT raised in majority of cases.

Most of the cases in our study with raised S.G.O.T and S.G.P.T presented in the 2 nd week of fever. Similar trend of abnormal LFTs were found by Moegestern R. [6] who studied the causes of liver involvement during the first three week of typhoid fever. In this study hepatomegaly was found during the $2^{\text {nd }}$ or $3^{\text {rd }}$ week more often in the $1^{\text {st }}$ week. Alkaline phosphatase, AST and ALT were raised in $100 \%, 100 \%$ and $91 \%$ of cases respectively during the $2^{\text {nd }}$ and $3^{\text {rd }}$ week but during the first week only $11 \%, 89 \%$ and $56 \%$ had mild increase [5].

Ozen H, Secmeer Get el [13] observed abnormal liver enzyme level in typhoid fever indicating liver involvement in $50 \%$ of the patients.

In another study by M Misadree et al [14] on evaluating the major source of increased serum enzyme level during typhoid fever, showed that hepatomegaly was revealed in $14 \%$ of the cases, which was much less than in our study in which hepatomegaly was found in 35\% cases.Similarly ALT was elevated in only $22 \%$ of cases in their study.

\section{Conclusion}

A prospective study of 54 cases was carried out over a period of one year to see the affection of liver functions in typhoid fever among children. Majority of the cases [40.74\%] were in the age group of 4-8 years of age. The commonest symptoms encountered in our study were abdominal pain (66.66\%), loss of appetite (62.96\%) and vomiting $(51.85 \%)$. Hepatomegaly was noted in $35 \%$ of cases.

S.G.O.T and S.G.P.T were marginally raised on admission in half of cases and most of them were in their second week of illness. S.G.O.T was raised in 27 $(50 \%)$ cases and S.G.P.T was raised in $25(46 \%)$ cases 
out of total 54 cases. Hence signifying affection of liver functions in majority of cases of typhoid fever as shown by many studies before. Most of these changes were partially reversed at the time of discharge.

Raised bilirubin was seen in only $4 \%$ of the cases. Thus liver functions can be deranged in many cases in the absence of jaundice.

Here we have recorded liver functions in all diagnosed typhoid patients but further studies are required to know the details effects of liver functions.

\section{Funding: Nil, Conflict of interest: Nil \\ Permission from IRB: Yes}

\section{Bibliography}

1. Osler W. Heptic complications of typhoid fever. Johns Hopkins. Hosp. Rep. 1899; 8: 373- 377.

2. De Brito T, Trench-vieira W, D Agostino- Dias. Jaundice in typhoidhepatitis; A light and electron microscopy study based onbiopsies. Acta Heppato Gastroenterol 1977; 24: 426- 433.

3. Khosla SN, Singh R, Singh GP, Trehan VK. The spectrum of hepatic injury in enteric fever. Am J Gastroenterol. 1988 Apr;83(4):413-6.

4. Ramachandran S, Godfrey JJ, Perera MV. Typhoid hepatitis. JAMA. 1974 Oct 14;230(2):236-40.

5. STUART BM, PULLEN RL. Typhoid; clinical analysis of 360 cases. Arch Intern Med (Chic). 1946 Dec;78(6):629-61.

6. Morgenstern R, Hayes PC. The liver in typhoid fever: always affected, not just a complication. Am J Gastroenterol. 1991 Sep;86(9):1235-9.
7. Tohme A, Zein E, Nasnas R. [Typhoid fever. Clinical and therapeutic study in 70 patients]. J Med Liban. 2004 Apr-Jun;52(2):71-7.

8. Jagadish K, Patwari AK, Sarin SK, Prakash C, Srivastava DK, Anand VK. Hepatic manifestations in typhoid fever. Indian Pediatr. 1994 Jul;31(7):807-11.

9. Dr. Srikanth. N MD, Dr. Santhosh Kumar. M MD IOSR-JDMS e- ISSN: 2279-0853, p-ISSN: 2279-0861. Volume 14, Issue 3 Ver. VI (Mar. 2015), PP17-24.

10. Farzanashafqat, ZafarIqbal, Anwaar A. Khan, FarrukhIqbal, AltafAlam, Arshad Kamal Butt,Waqar Hassan Shah Dept of medicine and gastroenterology, sheikh Zayed Hospital, Lahore. Hepatic involvement with typhoid fever, proceeding S.Z.P.G.M.I vol: 8(1-2) 1994, pp. 38-42.

11. Ali Hassan A bro, Ahmed MS Abdou, Jawahar L. Gangwani, Abdulla Mustadi, nadeem J Younis, Hina Seyada Hussaini Rashid Hospital Dubai Hematological and biochemical changes in typhoid fever. Pak J Med Sci 2009;25(2):166-171.

12. M Rasoolinejad, N EsmailboorBazaz and B moghelAIhosein salmonella hepatitis Dept of infectious disease, Imam Khomeini hospital, School of medicine, Tehran University of Medical Sciences, Tehran, Iran.

13. Ozen H, Seçmeer G, Kanra G, Ecevit Z, Ceyhan M, Dursun A, Anlar Y. Typhoid fever with very high transaminase levels. Turk J Pediatr. 1995 AprJun;37(2):169-71.

14. M Misadaree, A Shirdel, F Rokneeon typhoid myopathy or typhoidhepatitis. Indian journal of medical microbiology, vol. 25, no. 4, oct- dec, 2007, pp.351-353. DOI: 10.4103/0255-0857.37337.

\section{How to cite this article?}

Jain H, Arya S, Ikram S, Mandloi R, Xess V. An assessment of liver function test in typhoid fever in children. Int J Pediatr Res.2016;3(7):493-497.doi:10.17511/ijpr.2016.i07.05. 